\title{
Debt to Asset Ratio, Growth Opportunity dan Cash Flow Terhadap Cash Holding pada Perusahaan Consumer Goods
}

\author{
Maya Agustina Tanjung1, Alfira ${ }^{2}$, Rasita $^{3}$, Jenny Alvina ${ }^{4}$, Cindy Khorico ${ }^{5}$ \\ 1,2,3,4,5 Fakultas Ekonomi Universitas Prima Indonesia, Indonesia
}

\begin{abstract}
Keywords:

$D A R$;

Growth

Opportunity;

Cash Flow and

Cash Holding

\section{Kata kunci:}

$D A R$;

Growth

Opportunity;

Cash Flow dan

Cash Holding

Abstract: An increase in bankruptcies that triggered the collapse of a number of lending institutions, and affected the whole world. In addition, the monetary crisis in 1998 also occurred because companies that borrowed in dollars had to face higher costs in paying their debts because at that time the dollar strengthened to touch the level of Rp. 14,150, as a result the company was unable to pay its debts and went bankrupt. This study aims to analyze the Debt to Asset Ratio, Growth Opportunity and Cash Flow of Cash Holding conducted in the Consumer Goods sector whose index is listed on the Indonesia Stock Exchange in the 2015-2019 research period. This study is a quantitative study that uses secondary data from financial statements obtained from the financial or annual reports of consumer goods companies. The data processing uses multiple linear regression analysis techniques. The results showed that DAR and Growth Opportunity had a negative effect on cash holding while other variables, namely cash flow, had a positive effect on cash holding. So, individually or simultaneously DAR, growth opportunity and cash flow have a significant influence on the cash holding. The implications of this research are expected to help companies in managing cash properly.

Abstrak: Terjadinya peningkatan kebangkrutan yang memicu ambruknya sejumlah lembaga peminjaman, dan berimbas keseluruh dunia. Selain itu, krisis moneter pada tahun 1998 juga terjadi karena perusahaan yang meminjam dalam dolar harus menghadapi biaya yang lebih tinggi dalam membayar hutangnya karena pada saat itu dolar menguat hingga menyentuh level Rp 14.150, akibatnya perusahaan tidak mampu membayar hutangnya dan bangkrut. Penelitian ini bertujuan untuk menganalisis Debt to Asset Ratio, Growth Opportunity dan Cash Flow terhadap Cash Holding yang dilakukan pada sektor Consumer Goods yang indeksnya tercatat di Bursa Efek Indonesia pada periode penelitian 2015-2019. Penelitian ini merupakan penelitian kuantitatif yang menggunakan data sekunder laporan keuangan yang didapatkan dari laporan keuangan atau tahunan perusahaan consumer goods. Pengolahan datanya menggunakan teknik analisis regresi linear berganda. Hasil penelitian menunjukkan DAR dan Growth Opportunity memberi pengaruh yang negatif terhadap cash holding sedangkan variabel lainnya yaitu cash flow memberi pengaruh yang positif terhadap cash holding. Maka, secara individual maupun serempak DAR, growth opportunity dan cash flow memberi pengaruh yang berarti pada cash holdingnya. Implikasi penelitian ini diharapkan dapat membantu perusahaan dalam mengelola kas dengan baik.
\end{abstract}

Alamat Korespondensi:

E-mail: alvira123@yahoo.com (Tanjung)

\section{Pendahuluan}

Kas merupakan bentuk aktiva paling likuid yang digunakan untuk membiayai kebutuhan operasional perusahaan (Nailufar et al., 2018; Yocelyn \& Christiawan, 2013). Ketersediaan kas dalam suatu perusahaan sangat penting karena tanpa adanya kas kegiatan operasional perusahaan tidak dapat berjalan dengan baik (Bigelli \& Sánchez-Vidal, 2012; Dwi Aristi et al., 2021). Oleh karena itu, perusahaan harus menentukan jumlah kas agar sesuai dengan kebutuhan. Kas memiliki sifat yang likuid dan dapat digunakan untuk aktifitas operasional perusahaan. Pengelolaan kas dengan optimal sangat diperlukan agar perusahaan mampu bersaing dengan perusahaan lainnya (Astuti et al., 2019;

$\begin{array}{ll}\text { History: } & \\ \text { Received } & \text { : } 02 \text { Mei } 2021 \\ \text { Revised } & \text { : O3 Mei } 2021 \\ \text { Accepted } & : \text { 22 Juni } 2021 \\ \text { Published } & : \text { 25 Juli } 2021\end{array}$

Publisher: Undiksha Press

Licensed: This work is licensed under a Creative Commons Attribution 3.0 License 
Dwi Aristi et al., 2021). Perusahaan harus dapat mengelola ketersediaan kas dengan baik agar sesuai dengan kebutuhan perusahaan, karena apabila kas yang digunakan tidak optimal mengakibatkan aktivitas perusahaan tidak dapat dijalankan dengan baik. Oleh sebab itu, menjadi perhatian bagi kalangan eksekutif, analis, maupun investor terhadap penahanan kas (cash holding) untuk mengatur (manage) jumlah kas yang ideal bagi perusahaan.

Namun kenyataannya beberapa tahun sebelumnya, tepatnya pada tahun 2008 terjadi krisis keuangan di Amerika yang disebabkan oleh industri hipotek memberikan dana kepada para peminjam yang sebenarnya tidak mampu untuk memenuhi kewajibannya (Dwi Aristi et al., 2021; Marfuah \& Zulhilmi, 2015). Hal ini berakibat pada terjadinya peningkatan kebangkrutan yang memicu ambruknya sejumlah lembaga peminjaman, dan berimbas keseluruh dunia. Selain itu, krisis moneter pada tahun 1998 juga terjadi karena perusahaan yang meminjam dalam dolar harus menghadapi biaya yang lebih tinggi dalam membayar hutangnya karena pada saat itu dolar menguat hingga menyentuh level Rp 14.150, akibatnya perusahaan tidak mampu membayar hutangnya dan bangkrut(Astuti et al., 2019; Irwanto et al., 2018) Kejadian ini mengubah pandangan perusahaanperusahaan akan pentingnya menjaga likuiditasnya. Oleh karena itu penentuan kepemilikan kas harus benarbenar optimal yang sangat dibutuhkan oleh perusahaan. Uraian permasalahan mengenai keterkaitan DAR, Growth Opportunity dan Cash Flow dengan Cash Holding dapat ditelusuri lebih lanjut pada fenomena data yang menggambarkan jika permasalahan tersebut tidak selamanya terbukti.

Tabel 1. Fenomena

\begin{tabular}{llllll}
\hline Kode & Tahun & Hutang & Harga Saham & Arus Kas Operasi & Kas dan Setara Kas \\
\hline \multirow{6}{*}{ ADES } & 2015 & 324.855 .000 .000 & 1.015 & 26.040 .000 .000 & 24.068 .000 .000 \\
& 2016 & 383.091 .000 .000 & 1.000 & 119.156 .000 .000 & 35.316 .000 .000 \\
& 2017 & 417.225 .000 .000 & 885 & 87.199 .000 .000 & 25.507 .000 .000 \\
& 2018 & 399.361 .000 .000 & 920 & 146.588 .000 .000 & 102.273 .000 .000 \\
& 2019 & 254.438 .000 .000 & 1.045 & 184.178 .000 .000 & 129.049 .000 .000 \\
& 2015 & 398.991 .064 .485 & 430 & 62.869 .126 .110 & 91.875 .559 .378 \\
& 2016 & 362.540 .740 .471 & 440 & 136.703 .864 .740 & 58.393 .394 .361 \\
WIIM & 2017 & 247.620 .731 .930 & 290 & 194.599 .188 .956 & 54.065 .389 .750 \\
& 2018 & 250.337 .111 .893 & 141 & 140.978 .069 .476 & 87.056 .817 .897 \\
& 2019 & 266.351 .031 .079 & 168 & 199.249 .244 .086 & 265.018 .537 .191 \\
& 2015 & 910.758 .598 .913 & 3.015 & 194.843 .122 .728 & 9.815 .172 .239 \\
& 2016 & 1.168 .695 .057 .385 & 3.190 & 167.450 .246 .168 & 24.759 .150 .419 \\
STTP & 2017 & 957.660 .374 .836 & 4.360 & 301.239 .769 .296 & 69.954 .867 .440 \\
& 2018 & 984.801 .863 .078 & 3.750 & 245.006 .975 .842 & 64.106 .808 .475 \\
& 2019 & 733.556 .075 .974 & 4.500 & 499.922 .010 .752 & 100.727 .141 .756 \\
\hline
\end{tabular}

Berdasarkan tabel 1.1 dapat dilihat pada PT. Akasha Wira International, Tbk memiliki hutang yang meningkat di tahun 2016 namun tidak diikuti oleh penurunan kas nya sebaliknya kasnya malah meningkat. Pada PT. Wismilak Inti Makmur, Tbk memiliki harga saham yang meningkat di tahun 2016 namun tidak diikuti dengan meningkatnya kas malah sebaliknya kas menurun begitu juga di tahun 2018 harga sahamnya turun yang diikuti dengan peningkatan kasnya. Pada PT. Siantar Top, Tbk arus kas operasinya tahun 2016 mengalami penurunan akan tetapi kas di akhir tahun malah meningkat. Salah satu faktor yang mempengaruhi cash holding yang pertama adalah debt to asset ratio. Debt to Asset Ratio adalah salah satu bagian dari rasio leverage. yaitu rasio yang membandingkan jumlah utang terhadap aset. Rasio ini sangat penting bagi kreditur karena dapat mengukur seberapa tinggi risiko utang yang diberikan kepada debitur (Fosu, 2013; Rinaldi \& Cheisviyanny, 2015). Kedua yaitu faktor yang mempengaruhi cash holding adalah cash flow atau arus kas. Diperkirakan adanya hubungan yang positif antara cash flow dan cash holding (Astuti et al., 2019). Pecking order theory menjelaskan bahwa perusahaan akan memegang kas dalam jumlah besar ketika cash flow 
yang dimiliki tinggi. Perusahaan menyediakan uang kas pada tingkat yang maksimal dengan mempertimbangkan biaya dan keuntungan marginal dari memegang kas. Salah satu kelebihan cash holding yaitu dapat dimanfaatkan untuk menghadapi adanya kesulitan keuangan atau financial distress, penentuan investasi yang lebih maksimal pada saat muncul kesulitan keuangan dan hal-hal yang berhubungan dengan pendanaan eksternal.

Temuan penelitian sebelumnya menyatakan perusahaan yang memiliki tingkat leverage yang lebih rendah menunjukkan bahwa pendanaan perusahaan berasal dari modal sendiri. Perusahaan dengan rasio hutang yang tinggi memiliki cadangan kas yang rendah dikarenakan mereka harus membayar cicilan hutang mereka ditambah dengan bunganya (Andika et al., 2017; Putra \& Sunarto, 2021). Perusahaan yang tingkat leverage-nya tinggi akan menghasilkan tingkat cash holding yang kecil (Nofryanti, 2014). Cash flow memiliki pengaruh yang kuat terhadap cash holding (Gunawan, 2016). Sedangkan temuan lain menyatakan bahwa cash flow tidak mempengaruhi cash holding (Dwi Aristi et al., 2021). Penelitian tentang cash holding masih dianggap belum cukup untuk membuktikan tentang motivasi perusahaan dalam memegang kas secara berlebih, sehingga perlu dilakukan penelitian tentang determinant cash holding perusahaan. Perusahaan dengan tingkat peluang pertumbuhan yang besar, memegang kas dalam jumlah yang besar. Untuk berjaga-jaga biasanya perusahaan dengan peluang pertumbuhan yang besar akan menahan kas yang cukup besar sampai adanya peluang untuk menggunakan kas yang telah ditahan untuk digunakan pada kesempatan yang akan memberikan nilai tambah bagi perusahaan. Selain adanya keuntungan dalam memegang kas, terdapat kelemahan dalam memiliki kas dalam jumlah yang berlebihan. Oleh sebab itu perusahaan harus menyeimbangkan arus kas masuk dengan arus kas keluar dengan kebutuhan kas di tangan (cash holding) agar kas disediakan dalam batas jumlah yang telah ditentukan, tidak mengalami kekurangan ataupun kelebihan. Tujuan penelitian ini menganalisis pengaruh debt to asset ratio, growth opportunity dan cash flow terhadap cash holding pada perusahaan consumer goods yang tercatat di BEI Periode 201-2019. Adanya penelitian ini diharapkan dapat membantu perusahaan dalam mengelola keuangan.

\section{Metode}

Penelitian ini merupakan penelitian kuantitatif sehingga dalam mengintrepretasikan data yang telah dianalisis peneliti menggunakan deskriptif. Total populasi consumer goods periode 20152019 terdapat 52 perusahaan. Teknik penentuan sampel dalam penelitian ini adalah berdasarkan pertimbangan dan kriteria yang ditetapkan. Adapun kriteria pemilihan sampel ini adalah consumer goods yang listed di BEI dan consumer goods yang mempublikasikan laporan keuangan secara lengkap tahun 2015-2019.

Tabel 1. Tabel Pemilihan Sampel

\begin{tabular}{lll}
\hline No & Keterangan & Jumlah \\
\hline 1. & Consumer Goods yang listed di BEI & 52 \\
2. & $\begin{array}{l}\text { Consumer Goods yang tidak mempublikasikan laporan keuangan secara lengkap } \\
\text { tahun 2015-2019 }\end{array}$ & 11 \\
\hline & Jumlah sampel & $\mathbf{4 1}$ \\
\hline & Jumlah periode & $\mathbf{5}$ \\
\hline & Jumlah Observasi $=\mathbf{4 1} \times \mathbf{5}$ & $\mathbf{2 0 5}$ \\
\hline
\end{tabular}

Teknik pengumpulan data dalam penelitian ini dilakukan dengan teknik dokumentasi : mengumpulkan sumber data laporan keuangan consumer goods yang telah diaudit pada tahun 20152019. Penelitian ini menggunakan data kuantitatif yang bersumber dari data sekunder yang diambil dari situs www.idx.co.id dalam bentuk laporan keuangan consumer goods. Teknik analisis data menggunakan statistika deskriptif dan inferensial. Asumsi klasik adalah syarat statistik mutlak dilakukan pada regresi berganda. Syarat tersebut apabila telah dipenuhi, maka model regresi linear tersebut dikatakan Best Linear Unbiased Estimation. Adapun uji asumsi klasik pada penelitian ini 
yaitu uji normalitas, uji multikolinearitas, uji autokorelasi dan uji heteroskedastisitas. Penelitian ini menggunakan teknik analisis regresi linear berganda. Uji t untuk menguji bagaimana pengaruh masing-masing variabel bebasnya secara parsial terhadap variabel terikatnya. Uji $F$ adalah uji untuk melihat apakah semua variabel bebasnya secara bersama-sama berpengaruh terhadap variabel terikatnya

\section{Hasil dan Pembahasan}

\section{Hasil Penelitian}

Berdasarkan jumlah data yang diobservasi berjumlah 195 data yang berasal dari 39 sampel perusahaan sebanyak 5 tahun periode dari 2015-2019. Diperoleh hasil penelitian nilai minimum pada DAR sebesar 0,039 yang diperoleh PT. Inti Agri resources, Tbk di tahun 2015 dan nilai maksimum sebesar 2,900 yang diperoleh PT. Tiga Pilar Sejahtera Food, Tbk tahun 2018. Nilai rata-rata DARsebesar 0,43782. Growth Opportunity memiliki nilai minimum sebesar $-1,173$ yang diperoleh PT.Bentoel Internasional Investama, Tbk di tahun 2015 dan nilai maksimum sebesar 82,444 yang diperoleh PT. Unilever Indonesia, Tbk di tahun 2017. Nilai rata-ratanyasebesar 5,88602. Cash Flow memiliki nilai minimum sebesar -Rp 1.082.279.000.000,- yang diperoleh PT. Bentoel Internasionallnvestama, Tbk di tahun 2016 dan nilai maksimum sebesar Rp 18.820.695.000.000,yang diperoleh PT. HM Sampoerna, Tbk di tahun 2019. Nilai rata-rata sebesar Rp 1.195.365.899.059,6. Cash Holding memiliki nilai minimum sebesar -0,169 yaitu pada PT. Sekar Laut, Tbk tahun 2018dengan nilai maksimum sebesar 0,632 pada PT. Delta Djakarta, Tbk tahun 2018 dan nilai rata-rata sebesar 0,11046 . Adapun data pada penelitian yang diolah tidak memenuhi asumsi normalitas karena nilai signifikan yang diperoleh sebesar 0,043<0,05 sehingga perlu dilakukan pengobatan pada data menggunakan transformasi LN. Adapun hasil uji normalitas setelah LN pada gambar 1.

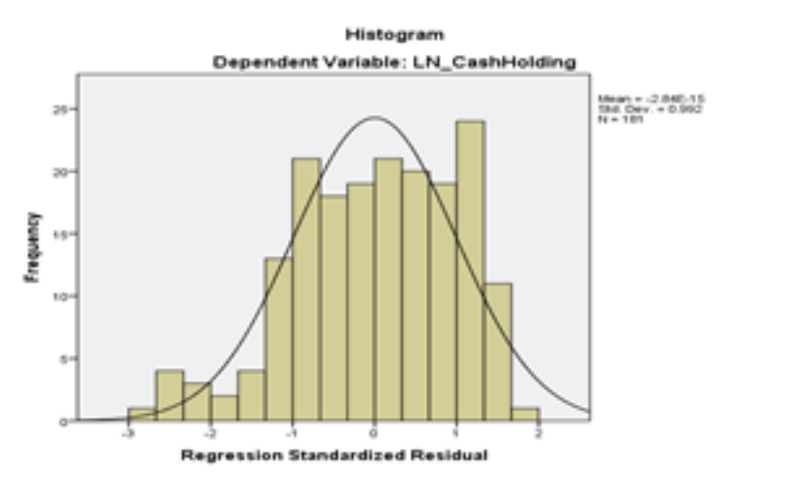

Gambar 1. Uji Normalitas Histogram

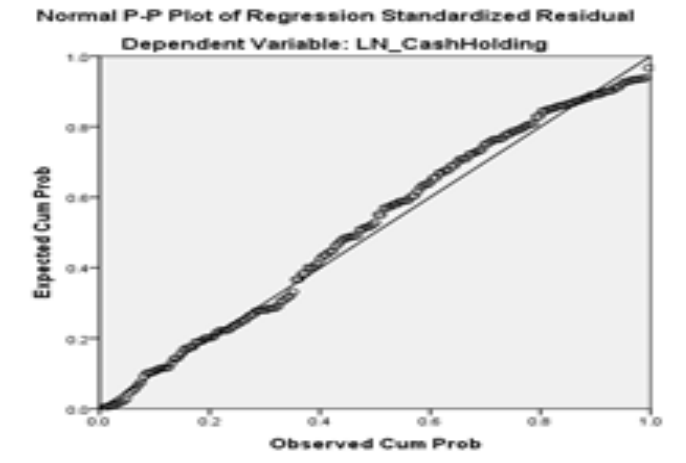

Gambar 2. Uji Normalitas P-P Plot

Grafik histogram menunjukkan setelah transformasi data telah memiliki distribusi normal karena visual grafik berbentuk simetris tidak menceng ke kanan atau ke kiri. Selain histogram asumsi normalitas juga dapat dilihat dari grafik P-Plot. Sedangkan, grafik P Plot menunjukkan data memiliki distribusi normal yang dapat dilihat dari plot yang bergerak mengikuti garis diagonal. Hasil olahan data diperoleh nilai signifikan yaitu 0,586 >0,05 maka dapat diambil kesimpulan jika data setelah di transformasi telah memenuhi asumsi normalitas. Uji multikolinearitas merupakan syarat asumsi kedua setelah normalitas. Untuk melihat apakah diantara variabel independen tidak memiliki korelasi maka dapat dilihat nilai tolerance dan VIF. Dari hasil pengujian multikolinearitas menunjukkan variabel independen tidak saling berkorelasi karena nilai tolerance masing-masing variabel bebas telah lebih besar dari 0,10 dan nilai VIF dari masing-masing variabel bebas telah lebih kecil dari 10. Selanjutnya dilakukan uji autokorelasi, regresi yang baik harus memenuhi asumsi ketiga yaitu tidak terjadi korelasi. Pengolahan data menghasilan nilai signifikan pada run test yaitu 0,602 yang mana nilai ini lebih tinggi dari 0,05 maka dapat disimpulkan uji data ini tidak terjadi autokorelasi. Uji heteroskedastisitas pada penelitian ini menggunakan metode grafik dan statistik, dimana metode 
statistik yang dipilih menggunakan uji Glejser. Dari hasil uji grafik scatterplot data menunjukkan plot telah tersebar secara acak sehingga data pada penelitian ini telah memenuhi syarat uji asumsi klasik karena tidak terjadi heteroskedastisitas. Dari hasil uji Glejser, menunjukkan data pada penelitian ini tidak terjadi heteroskedastisitas karena nilai signifikan dari tiga variabel bebas (DAR, Growth Opportunity, dan Cash Flow) lebih besar dari ketentuan nilai signifikan. Persamaan regresi berganda pada penelitian ini yaitu:

\section{Cash Holding $=-15,679-0,545$ DAR- 0,125Growth Opportunity + 0,481Cash Flow}

Dari persamaan regresi berganda tersebut dapat dijelaskan konstanta (a) sebesar -15,679 artinya jika variabel bebas (DAR, Growth Opportunity dan Cash Flow) konstan atau bernilai 0 maka Cash Holding akan senilai $-15,679$ satuan. $b_{1} X_{1}$ sebesar $-0,545$ artinya setiap peningkatan DAR sebanyak 1 satuan akan menyebabkan penurunan pada Cash Holding sebesar 0,545 satuan. $\mathrm{b}_{2} \mathrm{X}_{2}$ sebesar -0,125 artinya setiap peningkatan Growth Opportunity sebanyak 1 satuan akan menyebabkan penurunan Cash Holding sebesar 0,125 satuan. $b_{3} X_{3}$ sebesar 0,481 artinya setiap peningkatan Cash Flow sebanyak 1 satuan akan menyebabkan peningkatan Cash Holding sebesar 0,481 satuan. Besarnya pengaruh dari variabel independen terhadap variabel dependen dilihat dari nilai Adjusted R Square sebesar 0,685 yang berarti sebesar 68,5\% dari variasi Cash Holding yang dapat dijelaskan oleh variabel tiga variabel independen yaitu (DAR, Growth Opportunity, dan Cash Flow) dimana sisanya sebesar $31,5 \%$ dipengaruhi oleh faktor lain misalnya variabel modal kerja, ukuran perusahaan dan lainnya. Besarnya nilai $\mathrm{F}$ tabel untuk df $1=3$ dan df $2=177$ yaitu sebesar 2,66. Dengan melihat hasil uji $F$ diperoleh nilai $F$ hitung $(131,197)>F$ tabel 2,66 dan nilai signifikan $0,000<0,05$ maka Ha diterima yang berarti secara serempak ketiga variabel yaitu DAR, Growth Opportunity dan Cash Flow berpengaruh signifikan terhadap Cash Holding pada perusahaan Consumer Goods yang tercatat di BEI periode 2015-2019.

Besarnya t tabel pada alpha 0,05 (two tailed), df 177 adalah 1,97346. Dengan membandingkan hasil uji secara parsial tersebut dengan besarnya $t$ tabel maka hasil uji $t$ untuk variabel DAR yaitu nilai $-\mathrm{t}_{\text {hitung }}<-\mathrm{t}_{\text {tabel }}$ atau $-4,617<-1,97346$ dan nilai signifikan $0,000<0,05$ maka berarti Ha dterima artinya DAR berpengaruh secara negatif dan bersignifikan terhadap Cash Holding pada perusahaan Consumer Goods yang tercatat di BEI periode 2015-2019. Hasil uji t untuk variabel Growth Opportunity yaitu nilai $-\mathrm{t}_{\text {hitung }}<-\mathrm{t}_{\text {tabel }}$ atau $-2,414<-1,97346$ dan nilai signifikan $0,017<0,05$ maka Ha diterima artinya Growth Opportunity berpengaruh secara negatif dan bersignifikan terhadap Cash Holding pada perusahaan Consumer Goods yang tercatat di BEI periode 2015-2019. Hasil uji t untuk variabel Cash Flow yaitu nilai $t_{\text {hitung }}>t_{\text {tabel }}$ atau 17,616 $>1,97346$ dan nilai signifikan $0,000<0,05$ maka Ha diterima Cash Flow berpengaruh secara positif dan bersignifikan terhadap Cash Holding pada perusahaan Consumer Goods yang tercatat di BEI periode 2015-2019.

Temuan pertama, hasil penelitian menunjukkan bahwa DAR berpengaruh negatif dan bersignifikan terhadap Cash Holding. Hasil penelitian terdahulu Marfuah dan Zulhilmi (2015) juga menunjukkan variabel DAR berpengaruh negatif dan bersignifikan terhadap Cash Holding. Dengan meningkatnya hutang atau dengan menggunakan hutang yang terlalu besar dapat menyebabkan perusahaan harus melepaskan sebagian kasnya untuk membayar hutang sehingga sesuai dengan hasil penelitian peningkatan DAR dapat memberi pengaruh yang negatif yang artinya dapat menyebabkan penurunan pada tingkat cash holdingnya. Leverage merupakan rasio yang digunakan untuk mengukur sejauh mana aktiva perusahaan dibiayai utang (Almilia \& Kristijadi, 2003; Irwanto et al., 2018). DAR ini bernilai rendah karena berarti tingkat keamanan dananya semakin baik. Hal ini karena rasio utang menunjukkan sejauh aman utang yang bisa ditutupi oleh aktiva. Semakin kecil rasio, semakin aman pencatatan transaksi keuangannya (Dwi Aristi et al., 2021; Yanti \& Wati, 2018a). Hal ini dikarenakan perusahaan menggunakan kas tersebut untuk membayar sejumlah kewajiban dan bunga yang akan jatuh tempo sehingga akan mempengaruhi cash holding yang dimiliki perusahaan. Perusahaan dengan tingkat leverage yang lebih besar menunjukkan perusahaan tersebut memiliki kemampuan untuk mendapatkan pendanaan eksternal lebih mudah dan murah sehingga memungkinkan perusahaan untuk mengurangi jumlah kas yang dipegang. 
Temuan kedua membuktikan Growth Opportunity berpengaruh secara negatif terhadap Cash Holding. Perusahaan dengan growth opportunity yang besar memiliki kecenderungan dengan kebijakan cash holdings yang rendah. Hal ini dikarenakan perusahaan tersebut akan menarik perhatian para investor melalui growth opportunities untuk berinvestasi. Hasil penelitian diperkuat dengan temua yang menunjukkan Growth Opportunity berpengaruh negatif dan bersignifikan terhadap Cash Holding (Dwi Aristi et al., 2021). Growth opportunity ialah peluang pertumbuhan dengan mengukur harga saham di pasar modal dengan harga saham perusahaan (Sari \& Zoraya, 2021; Yanti \& Wati, 2018b). Perusahaan dengan growth opportunities yang baik pada umumnya membutuhkan dana yang besar untuk mendanai investasi di masa depan (Saputri \& Kuswardono, 2019; Wulandari \& Setiawan, 2019). Growth opportunity atau peluang pertumbuhan membutuhkan dana yang tidak sedikit sehingga menguras kas yang ada, sesuai dengan teori yang ada peluang pertumbuhan menyebabkan rendahnya tingkat cash holding perusahaan. Growth opportunity yang semakin meningkat akan dilihat oleh investor sebagai sinyal yang baik bagi pertumbuhan perusahaan di masa depan. Hal ini menandakan bahwa perkembangan perusahaan dianggap sebagai tanda dari adanya aspek yang menguntungkan dengan harapan memperoleh pengembalian investasi yang lebih baik oleh investor.

Hasil penelitian membuktikan cash flow berpengaruh secara positif dan bersignifikan terhadap Cash Holding. Karena saat cash flow yang masuk pada perusahaan besar maka perusahaan menggunakannya untuk membayar dividen, ditahan sebagai kas, membayar liabilitas. Oleh karena itu, untuk arus kas masuk yang besar tergantung pada operasional suatu perusahaan. Maka diharapkan perusahaan memperhatikan arus kas perusahaan tersebut. Saat arus kas masuk yang besar maka cash flow yang dimiliki perusahaan tersebut positif. Cash flow yang positif menyebabkan meningkatkanya tingkat cash holding yang tersedia di perusahaan (Ernayani et al., 2018; Trisnawati, 2013). Cash Flow berpengaruh secara positif dan bersignifikan terhadap Cash Holding (Astuti et al., 2019; Yanti \& Wati, 2018b). Semakin tinggi arus kas (cash flow) yang dimiliki oleh perusahaan akan meningkatkan kas yang dapat ditahan (cash holdingnya).

\section{Simpulan}

Berdasarkan hasil penelitian menunjukkan DAR, Growth Opportunity, dan Cash Flow mempengaruhi Cash Holding pada perusahaan Consumer Goods yang tercatat di BEI periode 20152019 secara signifikan. DAR berpengaruh negatif dan bersignifikan terhadap Cash Holding. Growth Opportunity berpengaruh secara negatif dan bersignifikan terhadap Cash Holding. Cash Flow berpengaruh secara positif dan bersignifikan terhadap Cash Holding. Bagi perusahaan consumer goods diharapkan agar tidak hanya berfokus pada penjualan secara offline saja, dikarenakan jika perusahaan dapat meningkatkan penjualannya maka perusahaan dapat meningkatkan cash holdingnya.

\section{Daftar Pustaka}

Almilia, L. S., \& Kristijadi. (2003). Analisis Rasio Keuangan Untuk Memprediksi Kondisi Financial Distress Perusahaan Manufaktur Yang Terdaftar Di Bursa Efek Jakarta. Jurnal Akuntansi dan Auditing Indonesia, 7(2), 183-210. http://www.jurnal.uii.ac.id/index.php/JAAl/article/view/846.

Andika, S., Efni, Y., \& Rokhmawati, A. (2017). Analisis Pengaruh Cash Convertion Cycle, Leverage, Net Working Capital, dan Growth Opportunity terhadap Cash Holdings Perusahaan (Studi Kasus pada Perusahaan Industri Barang Konsumsi di Bursa Efek Indonesia Periode 20102015). JOM Fekon, 4(1), 1479-1493.

Astuti, A. W., Wiyono, G., \& Mujino, M. (2019). Analisis Cash Holding Berbasis Kekuatan Kas Dan Modal Kerja Bersih. JBTI: Jurnal Bisnis Teori Dan Implementasi, 10(2), 137-149. https://doi.org/10.18196/bti.102123.

Bigelli, M., \& Sánchez-Vidal, J. (2012). Cash Holdings In Private Firms. Journal Of Banking And Finance, 36(1), 26-35. https://doi.org/10.1016/J.Jbankfin.2011.06.004. 
Dwi Aristi, M., Khalida, M., \& Azmi, Z. (2021). Faktor-Faktor Yang Mempengaruhi Cash Holding Pada Perusahaan Sektor Industri Barang Konsumsi. Jurnal Akuntansi Dan Ekonomika, 11(1), 23-32. https://doi.org/10.37859/jae.v11i1.2520.

Ernayani, R., Prihandoyo, C., \& Abdiannur, A. (2018). Perubahan Arus Kas dan Pengaruhnya terhadap Return Saham. JSHP (Jurnal Sosial Humaniora Dan Pendidikan), 2(1), 1-10. https://doi.org/10.32487/jshp.v2i1.284.

Fosu, S. (2013). Capital structure, product market competition and firm performance: Evidence from South Africa. Quarterly Review of Economics and Finance, 53(2), 140-151. https://doi.org/10.1016/j.qref.2013.02.004.

Gunawan, R. (2016). Pengaruh Growth Opportunity, Net Working Capital, dan Cash Flow Terhadap Cash Holding Pada Perusahaan Manufaktur di BEl 2011-2014. Urnal Akuntansi, 4(1), 1-22. http://ejournal.unp.ac.id/students/index.php/akt/article/view/2349.

Irwanto, A. K., Purwanto, B., Sitepu, \& S. (2018). Pengaruh Arus Kas Terhadap Profitabilitas dan Kinerja Saham Emiten Kompas 100 di Bursa Efek Indonesia. Jurnal Manajemen Dan Organisasi, 8(3), 236. https://doi.org/10.29244/jmo.v8i3.22472.

Marfuah, M., \& Zulhilmi, A. (2015). Pengaruh Growth Opportunity, Net Working Capital, Cash Conversion Cycle Dan Leverage Terhadap Cash Holding Perusahaan. Jurnal Ekonomi Dan Pembangunan, 5(1), 32. https://doi.org/10.12928/Optimum.V5i1.7819.

Nailufar, F., Sufitrayati, \& Badaruddin. (2018). Pengaruh Laba dan Arus Kas Terhadap Kondisi Financial Distress Pada Perusahaan Non Bank Yang Terdaftar Di Bursa Efek Indonesia. Jurnal Penelitian Ekonomi Akuntansi (JENSI), 2(2), 147-162. https://doi.org/10.21067/jrma.v6i2.4219.

Nofryanti. (2014). Pengaruh Net Working Capital, Growth Opportunity dan Leverage Terhadap (Studi Empiris Pada Perusahaan Properti and Real Estate Yang Terdaftar Di BEI 2009-2013). Jurnal IImiah Akuntansi, 2(4).

Putra, B. A. I., \& Sunarto, S. (2021). Pengaruh Profitabilitas, Leverage, dan Kepemilikan Manajerial Terhadap Nilai Perusahaan dengan Corporate Social Responsibility Sebagai Variabel Moderasi. Ekonomis: Journal of Economics and Business, 5(1), 149. https://doi.org/10.33087/ekonomis.v5i1.195.

Rinaldi, \& Cheisviyanny, C. (2015). Pengaruh Profitabilitas, Ukuran Perusahaan dan Kompensasi Rugi Fiskal Terhadap Tax Avoidance ( Studi Empiris Pada Perusahaan Manufaktur Yang Terdaftar Di BEI Tahun 2010-2013 ). Seminar Nasional Ekonomi Manajemen Dan Akuntansi (Snema) Fakultas Ekonomi Universitas Negeri Padang, 472-483.

Saputri, E., \& Kuswardono, A. (2019). Pengaruh Profitabilitas, Leverage, Firm Size, dan Growth Opportunity Terhadap Cash Holding Perusahaan (Studi Kasus Perusahaan Manufaktur yang Terdaftar Pada Bursa Efek Indonesia Periode Tahun 2013-2017). Management, and Industry (JEMI), 2(2), 91-104. http://journal.bakrie.ac.id/index.php/JEMI/article/view/1889/1498.

Sari, M., \& Zoraya, I. (2021). Perusahaan Industri Sektor Barang Konsumsi Yang Terdaftar Di Bursa Efek Indonesia Tahun 2009-2018. Managament Insight: Jurnal Ilmiah Manajemen, 16(1), 6180. https://doi.org/10.33369/insight.16.1.61-80.

Trisnawati, W. (2013). Pengaruh arus kas operasi, investasi dan pendanaan serta laba bersih terhadap retur saham. Jurnal IImu Dan Riset Akuntansi, 1(1), 77-92.

Wulandari, E. A., \& Setiawan, M. A. (2019). Pengaruh Growth Opportunity, Net Working Capital, Cash Conversion Cycle Dan Dividend Payout Terhadap Cash Holding. Jurnal Eksplorasi Akuntansi, 1(3), 1259-1274. https://doi.org/10.24036/jea.v1i3.141.

Yanti, M. I., \& Wati, E. (2018a). Analisis Faktor-Faktor yang Berpengaruh Terhadap Cash Holdings. Global Financial Accounting Journal, 2(2), 32-40. https://doi.org/10.37253/gfa.v2i2.388.

Yanti, M. I., \& Wati, E. (2018b). Analisis Faktor-Faktor Yang Berpengaruh Terhadap Cash Holdings. Global Financial Accounting Journal, 2(2), 32-40.

Yocelyn, A., \& Christiawan, Y. J. (2013). Analisis Pengaruh Perubahan Arus Kas dan Laba Akuntansi Terhadap Return Saham pada Perusahaan Berkapitalisasi Besar. Jurnal Akuntansi Dan Keuangan, 14(2), 81-90. https://doi.org/10.9744/jak.14.2.81-90. 